\title{
Células Troncales en el Desarrollo y las Perspectivas de Reprogramación Celular para la Regeneración
}

\author{
Stem Cells in Development and the Perspectives of Cellular Reprogramming for Regeneration
}

\author{
Muñoz, L. \& Concha, M. L.
}

MUÑOZ, L. \& CONCHA, M. L. Células troncales en el desarrollo y las perspectivas de reprogramación celular para la regeneración. Int. J. Morphol., 30(4):1343-1347, 2012.

RESUMEN: Los organismos multicelulares se desarrollan a partir de una sola célula: el cigoto. A lo largo de su ontogenia, las células que derivan del cigoto despliegan distintos programas celulares, los cuales son estabilizados por mecanismos epigenéticos. Los programas de las células troncales son más inclusivos, siendo mayor el silenciamiento que la activación de genes durante el proceso de diferenciación celular. Experimentalmente, se ha logrado que células en estado de diferenciación terminal reactiven el programa de células troncales y recuperen su pluripotencialidad, proceso llamado reprogramación. Esto despierta esperanzas en el avance de una medicina regenerativa con nuevas capacidades para el tratamiento de enfermedades crónicas, sin las restricciones éticas del uso de células embrionarias.

PALABRAS CLAVE: Células troncales; Pluripotencialidad; Reprogramación celular; Factores de transcripción; Oct4; Sox2; Nanog; Medicina regenerativa.

\section{INTRODUCCIÓN}

Los organismos multicelulares están conformados por una gran diversidad de células, las que se organizan y especializan en funciones muy definidas para sostener la vida. Es impresionante que esa diversidad de formas y funciones deriven de una sola célula: el cigoto. Este, al dividirse, replica y transmite fielmente su genoma completo, de la misma forma que lo sigue haciendo toda su progenie cada vez que se vuelve a dividir. Sin embargo, el proceso de diferenciación celular implica que las células de diferente linaje utilizan distinta información, a partir de aquella disponible en su genoma. La selección de los genes que se expresan o se silencian en una célula determinada es el "programa" de esa célula y determina su compromiso de linaje. Este compromiso, es decir, la determinación del tipo celular en el cual se diferencia una célula, se adquiere durante el desarrollo embrionario. La imagen de la "adquisición de un compromiso" es adecuada, dado que expresa muy bien el hecho de que los estímulos o señales que provocan que una célula despliegue un determinado programa celular para formar parte, por ejemplo, del hígado o el cerebro, ocurren sólo durante el desarrollo embrionario. Posteriormente, existen mecanismos de "memoria" que permiten replicar el programa indicado cada vez que las células se dividen, mantenien- do la identidad celular (Bonasio et al., 2010). Todas las células de un organismo multicelular tienen exactamente la misma información genética, pero "adquieren el compromiso" de usar sólo una determinada parte de ella y no lo "olvidan”. ¿Cómo lo hacen?

En 1997, se publicó el nacimiento de Dolly. Se trataba de una oveja que había sido concebida por el transplante del núcleo de una célula somática en estado de diferenciación terminal proveniente de un organismo adulto, a un ovocito al que se le había retirado su propio núcleo. Este tipo de experimentos, llamados de "reprogramación celular mediante transferencia nuclear", demostraron en forma inequívoca que todas las células de un organismo adulto conservan la información genética capaz de llevar adelante el desarrollo de un organismo completo. Por lo tanto, la información genética no se pierde durante la diferenciación celular, es su expresión la que cambia a lo largo de la ontogenia celular (Jaenisch et al., 2008). Los programas son estables, pero los experimentos de "reprogramación" demuestran que son modificables. Desde el punto de vista de la aplicación biomédica, los conceptos que emanan de este tipo de experimentos sugieren que mediante la reprogramación celular 
se podría llegar a regenerar tejidos como estrategia de tratamiento de diferentes enfermedades degenerativas. Reprogramar implica, que células ya diferenciadas vuelvan a un estado pluripotencial y se rediferencien en el tipo celular de interés, que sirva como sustrato para regenerar tejidos de órganos que han fallado. Todo esto a partir de células obtenidas del mismo paciente. Ejemplos de estos tratamientos podrían ser la generación de células $B$ de los islotes pancreáticos, encargadas de producir la insulina, para el tratamiento de la Diabetes Mellitus tipo 1, la generación de neuronas de la Sustancia Nigra pars compacta en la enfermedad de Parkinson (Xu et al., 2010), o la regeneración de células troncales hematógenas después del tratamiento por quimioterapia de una leucemia. Sin embargo, aún estamos lejos de saber cómo se puede controlar la reprogramación celular. Para acceder a este tipo de conocimiento, parece lógico comenzar por intentar entender cómo se produce la programación en la naturaleza, es decir entender la ontogenia celular a lo largo del desarrollo.

Ontogenia Celular. El cigoto tiene que ser capaz de dar origen a todas las células embrionarias y extraembrionarias. A su vez, las primeras células embrionarias, llamadas células troncales embrionarias, tienen que ser capaces de dar origen a todas las células de un organismo adulto, pero no son capaces de dar origen a los tejidos extraembrionarios. A su vez, las células diferenciadas, cuyo potencial proliferativo es limitado, mientras pueden dividirse no pueden dar origen a células distintas a si mismas. En otras palabras, a medida que la ontogenia celular avanza, las células van perdiendo la potencialidad de dar origen a la gama de tipos celulares posibles. De totipotenciales, pasan a ser pluripotenciales y luego derivan en oligopotenciales, hasta perder toda potencialidad de diferenciarse en algo distinto a ellas mismas (Jaenisch et al). Si los programas celulares son combinatorias de expresión o represión estable de genes, intuitivamente se puede plantear que una célula pluripotencial expresa más genes que una célula terminalmente diferenciada. Si bien no se conocen exactamente los mecanismos involucrados en este proceso ontogénico, la evidencia existente apoya esta visión. En un modelo de diferenciación in vitro, se demostró que en el paso de una célula troncal embrionaria a una célula progenitora de neuronas, la relación entre silenciamiento de genes versus activación de genes es de 23:1. Es decir, en la adquisición de un compromiso de linaje son muchos más los genes que se reprimen que los que se activan (Mohn et al., 2008).

Reprogramación celular directa. Las células troncales embrionarias se definen por dos capacidades esenciales: la pluripotencialidad, que es la capacidad de generar una progenie que se diferencia en distintos tipos celulares, y la capacidad de autorrenovarse (Jaenisch et al.). Esto último se logra mediante divisiones mitóticas asimétricas, en las que una de las células hijas conserva las características de la célula madre, es decir sigue siendo célula troncal, y la otra adquiere nuevas características que la van diferenciando hacia un cierto linaje celular. La primera se mantiene siempre en el ciclo celular y conserva la capacidad de generar progenies de células troncales y/o de células diferenciadas en forma indefinida, mientras que la segunda en algún momento de su ontogenia pasa a la etapa G0 del ciclo celular. Las técnicas de reprogramación celular evolucionaron desde los experimentos de transferencia nuclear hasta que en 2006, Takahashi \& Yamanaka (2008) publicaron la reprogramación directa de una célula diferenciada sin afectar su integridad. Ellos reprogramaron fibroblastos mediante la transducción viral de cuatro factores de transcripción: Oct4, Sox2, c-myc y Klf4. Los dos primeros son factores de transcripción específicos de células troncales, asociados a pluripotencialidad. Los dos últimos son factores de transcripción oncogénicos u oncogenes. Posteriormente se ha demostrado que estos oncogenes son prescindibles para el éxito del proceso pero que aumentan importantemente su eficiencia, hasta que recientemente se logró realizar una reprogramación directa sólo mediante la transducción de Oct4 (Xu et al.). En estos experimentos, se obtuvo células en dos condiciones de reprogramación, una parcial y otra completa. Un análisis genómico integrativo de gran escala mostró que existía una diferencia entre estas dos condiciones en cuanto a la "remodelación epigenética". En las células que se reprogramaron sólo parcialmente existía una persistencia de la hipermetilación del ADN a nivel de islas $\mathrm{CpG}$ de los promotores de los principales factores de transcripción asociados a la pluripotencialidad. La utilización de un inhibidor de las ADN metiltransferasas durante la reprogramación provocó que la mayoría de las células se reprogramaran en forma completa y muy pocas quedaran en el estado intermedio (Mikkelsen et al., 2008). La explicación de este fenómeno es que, al evitar la metilación del ADN, los promotores de los factores de transcripción involucrados en la troncalidad quedan asequibles a sus factores de transcripción, pudiéndose activar el programa de troncalidad (Jaenisch et al.).

Los factores de transcripción centrales responsables de la mantención de la pluripotencialidad son Oct4, Sox 2 y Nanog. Sox 2 se expresa en forma más abundante que los otros dos y no es exclusivo de células pluripotenciales. Sin embargo, la presencia de Oct4, el cual se encuentra en baja expresión y es específico del estado pluripotencial, permite que Sox 2 y Oct 4 formen heterodímeros y se unan al promotor de Nanog, posibilitando su transcripción. Una vez presentes los tres factores, promueven la transcripción de genes propios de células troncales embrionarias, además de unirse a sus propios promotores, formando un circuito de retroali- 
mentación positiva consigo mismos y con los otros dos. Por lo tanto, mientras ellos estén presentes se autoperpetuarán logrando mantener este estado celular (Boyer et al., 2005) (Fig. 1). El inicio de la diferenciación no ocurre sin la represión activa de la transcripción mediante factores de transcripción represores, como primer evento y posteriormente silenciamiento epigenético. Posteriormente se produce la activación de la expresión de los genes propios del estado diferenciado, muchos de los cuales ya están siendo transcritos en el estado indiferenciado pluripotencial (Mohn et al.).

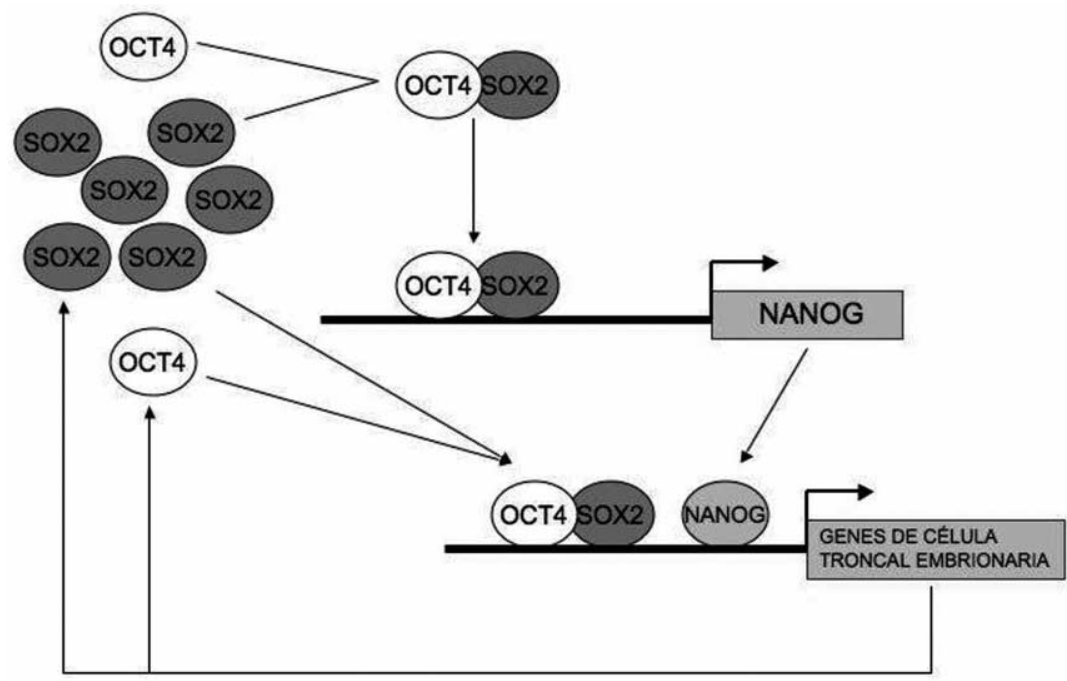

Fig. 1. Circuito central de pluripotencialidad celular formado por los factores de transcripción Oct4, Sox 2 y Nanog. Sox2, que es más abundante y ubicuo que los otros dos factores, forma heterodímeros con Oct4, el cual se expresa a bajos niveles y en forma específica en las células pluripotenciales. El heterodímero Oct4-Sox2 se une al promotor del gen Nanog, promoviendo el inicio de su transcripción. Oct4, Sox2 y Nanog promueven el despliegue del programa propio de células troncales embrionarias, incluyendo la promoción de su propia transcripción, formando un triple circuito de retroalimentación positiva que estabiliza ese estado celular.

Reprogramación celular en la naturaleza. El proceso por el cual una célula diferenciada termina adquiriendo otro fenotipo diferenciado, distinto al anterior, se denomina transdiferenciación. Existen en la naturaleza ejemplos de transdiferenciación de células adultas en condiciones fisiológicas. Uno de estos ejemplos es el de los blastemas en salamandras o peces cebra. En estos casos, células integras serían capaces de recibir mensajes del medio ambiente que les permite llevar a cabo el proceso de reprogramación. Este proceso tiene una fase de desdiferenciación hacia una célula troncal, la que se autorrenueva y prolifera, generando una progenie que evoluciona hacia estados diferenciados distintos al original. Esto permite que se regenere un segmento amputado específico (Han et al., 2005).

La regeneración es una respuesta local de las células del muñón, y atraviesa por una serie de etapas, que incluyen: cierre de la herida a nivel de la epidermis, desdiferenciación de los tejidos del muñón, transformación del epitelio en una estructura especializada llamada cresta apical epitelial o AEC (apical epithelial cap), que es requerida para el brote de la extremidad, migración de células desdiferenciadas al centro de la herida donde se forma el blastema y proliferación de las células del blastema. Una vez formado el blastema, se piensa que el proceso continúa de manera similar a lo que ocurre en el brote de un miembro durante el desarrollo embrionario, en cuanto a sus aspectos morfogenéticos, formación de patrones, y rediferenciación (Han et al.).

Perspectivas de la aplicación clínica de la reprogramación celular directa. $\mathrm{Re}$ cientemente se publicó la experiencia del uso de células inducidas a ser pluripotenciales, para el tratamiento de un modelo de enfermedad de Parkinson en ratas. La enfermedad de Parkinson es una enfermedad degenerativa caracterizada por la presencia de alteraciones motoras provocada por la pérdida de neuronas dopaminérgicas de la Sustancia Nigra del cerebro. Experimentalmente, se puede provocar la muerte específica de este tipo de neuronas en ratas mediante la administración intracerebral de 6-hidroxidopamina (6-OH-DA). Esto genera un cuadro de parkinsonismo. En el estudio, se reprogramó fibroblastos de estas ratas y se indujo su diferenciación a neuronas dopaminérgicas, las que posteriormente fueron implantadas en el cerebro de los mismos animales. Cuatro semanas después se vio una recuperación clínica evidente de las ratas implantadas con neuronas dopaminérgicas, en comparación con ratas a las cuales se sometió a la misma operación pero en las que no se dejó implante alguno. Cuatro semanas después también se realizó un examen histológico del cerebro de las ratas sometidas al implante, el que mostró presencia de un número significativo de células con morfologías complejas que presentaban marcadores moleculares de neuronas dopaminérgicas, estando el cuerpo celular en el sitio del implante pero emitiendo largas prolongaciones hacia estructuras cerebrales vecinas, tal como lo hacen las neuronas (Wernig et al., 2008).

Experimentos de este tipo despiertan la esperanza de estar frente a una nueva estrategia terapéutica. Las principales ventajas respecto a intentos terapéuticos 
previos con células madre, es que en estos procedimientos se realizan implantes con células propias del paciente, que evitan rechazos del sistema inmune, y que en estos casos no se requiere del uso de embriones, evitando así conflictos éticos. Sin embargo, su uso en seres humanos aún debe superar una gran escollo. La reprogramación celular realizada por transducción de genes mediante el uso de lentivirus, integra a estos genes en forma aleatoria en el genoma de la célula, pudiendo generar mutaciones oncogénicas en la célula y producir un cáncer en el paciente (Xu et al).

Reprogramación celular sin introducción de ácidos nucleicos. En 2009, se logró por primera vez la reprogramación de fibroblastos embrionarios con la transducción de proteínas recombinantes de los mismos factores de transcripción Oct4, Sox2, Klf-4 y c-myc. Esto superaría los riesgos oncogénicos de la reprogramación directa, sin embargo, tiene desventajas en cuanto a la corta vida media de las proteínas, necesitando aplicaciones repetidas, con una ineficiencia importante. Esta última ha sido mejorada con el uso de ácido valproico, un anticonvulsivante de uso habitual en seres humanos, que actúa inhibiendo la deacetilasa de histonas (HDAC) (Parameswaran et al., 2011).

Reprogramación celular mediante señales no autónomas. Esta aproximación interesante, es la que se acerca más a los mecanismos normales de la ontogenia celular durante el desarrollo. Se basa en que si células madre ya especificadas para un tejido en particular (células multipotentes) son colocadas en un ambiente propio de estadios del desarrollo embrionario más tempranos, ellas son capaces de reprogramarse hacia un estado pluripotente, como la de una célula madre embrionaria. De esta forma se puede dar origen a células de las tres capas embrionarias (ectodermo, mesodermo y endodermo), es decir, se está ante un proceso de transdiferenciación. Este ambiente se ha logrado en cultivo en forma sencilla, mediante el uso de medios condicionados por células de carcinoma embrionario. En ese medio de cultivo estarían las señales que son transducidas por las células reclutando su propia maquinaria de pluripotencialidad, sin aporte de moléculas exógenas al intracelular. Este proceso también es optimizable con el uso de fármacos inhibidores de deacetilasas o metiltrasferasas, facilitando la remodelación epigenética necesaria para la reactivación de la transcripcción de los genes de pluripotencialidad. No todos los tipos celulares son igualmente susceptibles a este tipo de reprogramación, probablemente dependiente de su estado transcripcional previo. Así, se ha visto que tipos celulares que ya expresan alguno de los factores reprogramadores, son más eficientemente reprogramables por cualquiera de los métodos mencionados. Dentro de los cuatro factores, la inducción de la transcripción de Oct4 sería el paso crítico, el cual al heterodimerizar con Sox2, de expresión menos restringida en distintos tipos celulares, promovería la transcripción de Nanog, completando el circuito central, que posteriormente se autoperpetúa, sosteniendo la condición pluripotencial (Parameswaran et al.).

\section{CONCLUSIONES}

La ontogenia celular está dada por señales autónomas y no autónomas que van modulando y estabilizando su programa celular. Este proceso es reversible, pudiendo generar nuevas identidades celulares, potencialmente útiles en medicina regenerativa humana. La seguridad y eficiencia de métodos de reprogramación libres de restricciones éticas por la ausencia de la necesidad de utilización de embriones en el proceso, está en pleno desarrollo. Siendo la tendencia natural a imitar los mecanismos utilizados por las células durante su desarrollo, para de esta forma evitar alterar su integridad.

MUÑOZ, L. \& CONCHA, M. L. Stem cells in development, and the perspectives of cellular reprogramming for regeneration. Int. J. Morphol., 30(4):1343-1347, 2012.

SUMMARY: Multicellular organisms develop from one cell: the zygote. During ontogeny, cells derived from the zygote display different cellular programs that are stabilized through epigenetic mechanisms. The programs of stem cells seem more inclusive, and during the process of differentiation a larger number of genes are silenced than activated. The reactivation of pluripotency recovers of the stem cell program in terminally differentiated cells has been achieved experimentally. This process, called reprogramming, brings new hope for the development of a regenerative medicine with new capabilities for the treatment of chronic diseases, without the ethic restrains imposed by the use of embryonic cells. medicine.

KEY WORDS: Stem cells, pluripotency, cellular reprogramming, transcription factors, Oct4, Sox2, Nanog, regenerative 


\section{REFERENCIAS BIBLIOGRÁFICAS}

Bonasio, R.; Tu, S. \& Reinberg, D. Molecular Signals of Epigenetic States. Science, 330:612- 6, 2010.

Boyer, L.; Lee, T. I.; Cole, M. F.; Johnstone, S. E.; Levine, S. S.; Zucker, J. P.; Guenther, M. G.; Kumar, R. M.; Murray, H. L.; Jenner, R. G.; Gifford, D. K.; Melton, D. A.; Jaenisch, R. \& Joung, R. A. Core Transcriptional Regulatory Circuitry in Human Embryonic Stem Cells. Cell, 122(6): 947-56, 2005.

Broches, J. P. Amphibian Limb Regeneration: Rebuilding a Complex Structure. Science, 276(5309):81-7, 1997.

Han, M.; Yang, X.; Taylor, G.; Burdsal, C. A.; Anderson, R. A. \& Muneoka, K. Limb Regeneration in Higher Vertebrates: Developing a Roadmap. Anat. Rec. B. New Anat), 287(1):14$24,2005$.

Jaenisch, R. \& Young, R. Stem Cells, the Molecular Circuitry of Pluripotency and Nuclear Reprogramming. Cell, 132: 567582, 2008.

Mikkelsen, T. S.; Hanna, J.; Zhang, X.; Ku, M.; Wernig, M.; Schorderet, P.; Bernstein, B. E.; Jaenisch, R.; Lander, E. S. \& Meissner, A. Dissecting direct reprogramming through integrative genomic analysis. Nature, 454:49-55, 2008.

Mohn, F.; Weber, M.; Rebhan, M. et al. Lineage-Specific Polycomb Targets and De Novo DNA Methylation Define Restriction and Potential of Neuronal Progenitors. Molecular Cell, 30:75566, 2008.

Parameswaran, S.; Balasubramanian, S.; Rao, M. S. \& Ahmad, I. Non-Cell Autonomous Reprogramming: a Nucleic Acid Free Approach to Induction of Pluripotency. Stem Cells, 29(7):1013$20,2011$.

Takahashi, K. \& Yamanaka, S. Induction of pluripotent stem cells from mouse embryonic and adult fibroblasts cultures by defined factors. Cell, 126:663-76, 2006.

Wernig, M.; Zhao, J-P.; Pruszak, J.; Hedlund, E.; Soldner, F.; Broccoli, V.; Constantine-Paton, M.; Isacson, O. \& Jaenisch, R. Neurons derived from reprogrammed fibroblasts functionally integrate into the fetal brain and improve symptoms of rats with Parkinson's disease. PNAS, 105 (15): 5856- 61, 2008.

Xu, L.; Tan, Y. Y.; Ding, J. Q. \& Chen, S. D. The iPS Technique Provides Hope for Parkinson's Disease Treatment. Stem Cell Rev and Rep., 2010.

\author{
Dirección para correspondencia: \\ Muñoz, L. Concha, M. L. \\ Laboratorio de Estudios Ontogénicos \\ Programa de Anatomía y Biología del Desarrollo \\ Facultad de Medicina \\ Universidad de Chile \\ Santiago \\ CHILE \\ Email: lamunoz@med.uchile.cl \\ mconcha@med.uchile.cl
}

Recibido : 23-07-2012

Aceptado: 28-08-2012 